\title{
¿Influyeron la cultura y el aprendizaje en la evolución humana?
}

\author{
Julio César Urbina Orantes
}

\begin{abstract}
Resumen
La civilización actual, con todo su avance científico y tecnológico, es la punta de un largo proceso de desarrollo que se remonta hasta el origen mismo de la especie humana. Damos por hecho que la evolución ha conducido al surgimiento de la cultura, puesto que ha determinado el crecimiento de las capacidades cerebrales de los homínidos. Pero también es posible que las manifestaciones culturales que gradualmente surgieron como frutos del avance de la inteligencia — tales como la fabricación y uso de herramientas, el dominio del fuego, el surgimiento de la agricultura y el nacimiento del lenguaje, entre otras - pudieran haber influido en las transformaciones evolutivas de los homínidos. El aprendizaje se inserta como una pieza clave, pero no está claro cómo acomodarlo en este complejo rompecabezas.
\end{abstract}

Palabras clave: evolución humana, cultura, aprendizaje, homínidos, cerebro.

\section{Did CUlture and LeARNING INFLUENCE hUMAN EVOLUTION?}

\begin{abstract}
Today's civilization, with all its scientific and technological advancement, is the tip from a long process of development that goes back to the very origin of humankind. We assume that evolution has led to the emergence of culture because it shaped the brain's capacities of hominids. But it is also possible that cultural manifestations that gradually emerged due to the increase of intelligence - like the making of tools, use of fire, emergence of agriculture, and the birth of language - might have influenced the evolutionary transformations of hominids. Learning is a key piece, but it is unclear how it fits in this complex puzzle.
\end{abstract}

Keywords: human evolution, culture, learning, hominids, brain.

Recepción: 20/06/2018. Aceptación: 20/05/2020.

Dol: http://doi.org/10.22201/cuaieed.16076079e.2020.21.5.3 
Julio César Urbina Orantes

juliocesarurbina@prodigy.net.mx

Biólogo, Maestro en Ciencias (Investigación Biomédica Básica) y Licenciado en Lengua y Literaturas Hispánicas; autor de artículos de divulgación científica, libro y capítulo de libro, presentaciones en eventos académicos, colaborador en una obra colectiva. Ha trabajado en áreas universitarias de planeación, consejo técnico, servicios escolares, y desde 2005 es Docente Tutor Investigador en el plantel "Ricardo Flores Magón", del Instituto de Educación Media Superior de la Ciudad de México.

Figura 1. Trinomio que muestra la interrelación entre evolución, cultura y aprendizaje. La evolución biológica ha determinado nuestras capacidades para aprender y para desarrollar la cultura, mediante las facultades cognitivas del cerebro. Las flechas continuas indican que la evidencia es sólida; las líneas discontinuas, posibles influencias.

\section{Introducción}

La civilización actual nos ofrece innumerables comodidades, muchas de las cuales son consecuencia de los avances científicos y del desarrollo de tecnología logrados por la humanidad. Pero la civilización es joven, si recordamos nuestros cursos de historia, los pueblos más antiguos que nos han dejado vestigios de su vida en comunidad apenas tendrán unos diez mil años. Sin embargo, el camino hacia la civilización comenzó mucho antes, de alguna forma paralela a la evolución de la especie. Recordemos que el ser humano, gracias al desarrollo de su inteligencia, ha modificado su entorno para protegerse y satisfacer sus necesidades. Esto ha conducido al florecimiento de la cultura, pues encontramos aquí una estrecha relación entre ésta y el desarrollo evolutivo de la especie. Una variable se añade a dicha ecuación: la extraordinaria facultad que tenemos los seres humanos de aprender. Aunque no sabemos bien cómo se ha establecido este trinomio, tal vez un poco de historia ayude a aclarar el panorama.

\section{Evolución biológica}
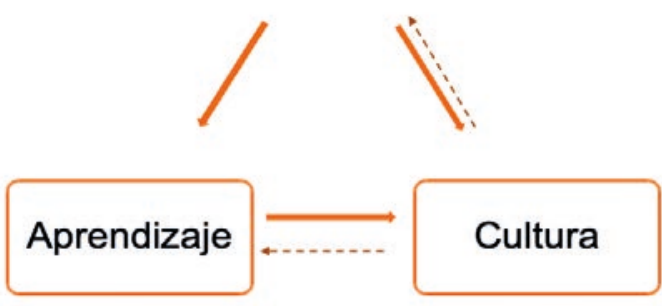


\section{El amanecer de la humanidad}

Si examinamos el desarrollo evolutivo del género humano, podemos apreciar, en las reconstrucciones de los fósiles de los ancestros más primitivos, cambios paulatinos en diversos rasgos anatómicos, tales como la columna vertebral, que facilitó mantener la posición erguida del cuerpo o el aumento gradual del volumen del cráneo. También descubriremos que el incremento de la capacidad cerebral parece haber conducido al desarrollo de la cultura. Pero vayamos paso a paso. El origen de la humanidad se remonta a hace seis millones de años aproximadamente, cuando la evolución de los primates dio lugar a dos linajes: por un lado, a los homínidos y, por el otro, a los simios africanos a los que en la actualidad pertenencen el chimpancé y el gorila (Leaky, 2002). Resultado de esa divergencia, surgieron las primeras especies relacionadas evolutivamente con el ser humano: los géneros Ardipithecus y Australopitecus. Se aprecian cambios marcados en la anatomía de los australo pitecinos que los separan definitivamente de los simios, como la posición erecta del cuerpo, que permitía a esos ejemplares caminar en dos piernas, y el tamaño de cráneo, mayor en proporción al de los simios. A partir de estos ancestros, hace alrededor de 2.5 millones de años surgió el género Homo. Los antepasados más cercanos al hombre moderno pertenecen a este género (Gore, 2002).

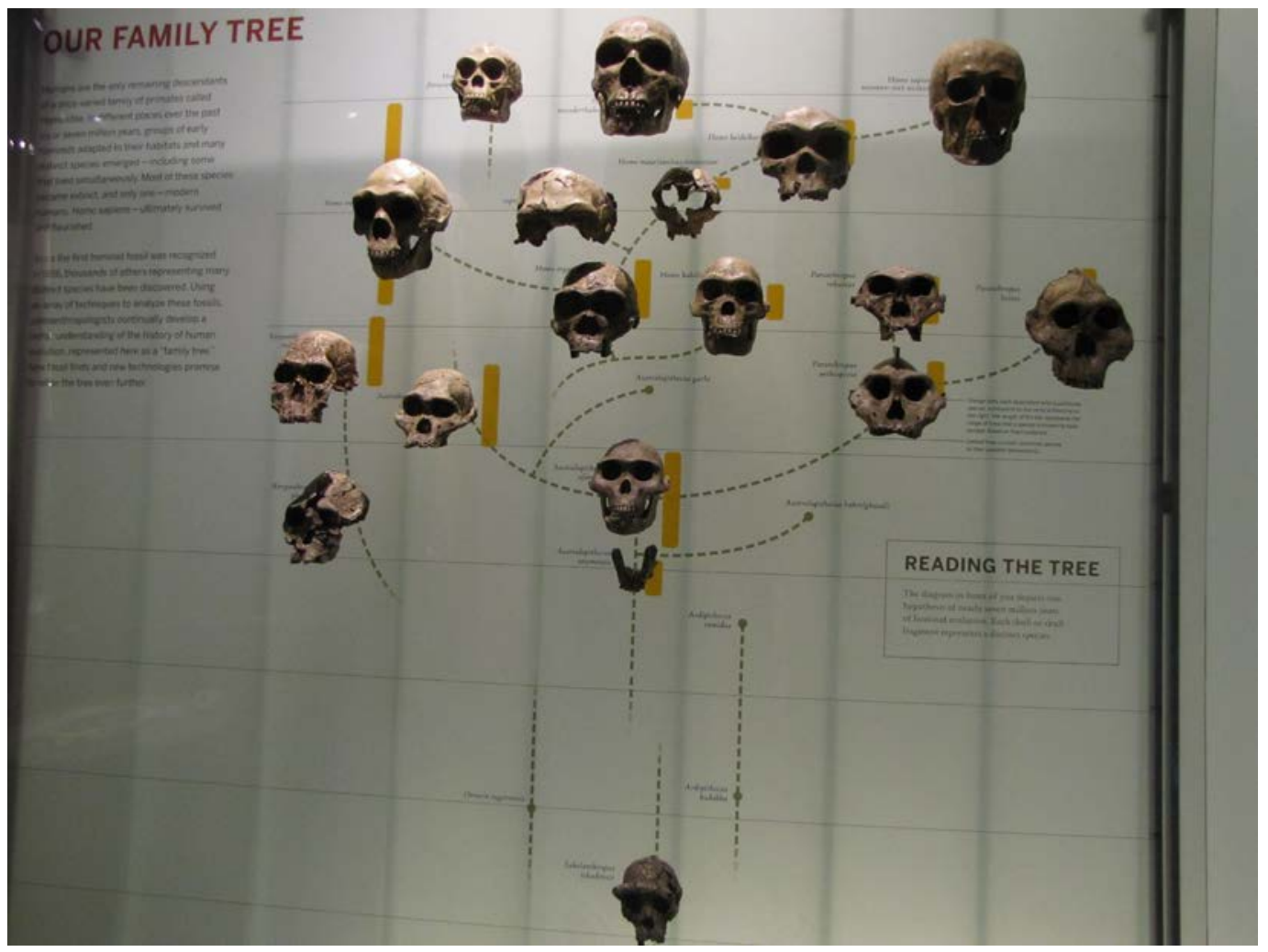

Los primeros homínidos tenían una capacidad encefálica equivalente a la mitad del promedio del ser humano actual. La presencia de herramientas de piedra 
indica que los ancestros del hombre tuvieron una incipiente actividad inteligente. Explico: usar herramientas es un comportamiento que se ha observado en primates, pero idear y construir una para determinado fin significa que ha habido actividad racional, pues cuando se construyen artefactos - por sencillos que éstos sean, como las primitivas hachas de mano-, se hacen con la intención de utilizarlos para cortar y desgarrar piel, carne y huesos. ¿Qué implica esto? Primero, que hay una necesidad, que puede resolverse si se cuenta con determinado instrumento; segundo, se imagina la herramienta y se planea cómo construirla; y tercero, se fabrica y se utiliza. La abundancia de hallazgos hacen pensar que esta tecnología - se considera así porque se modifican objetos

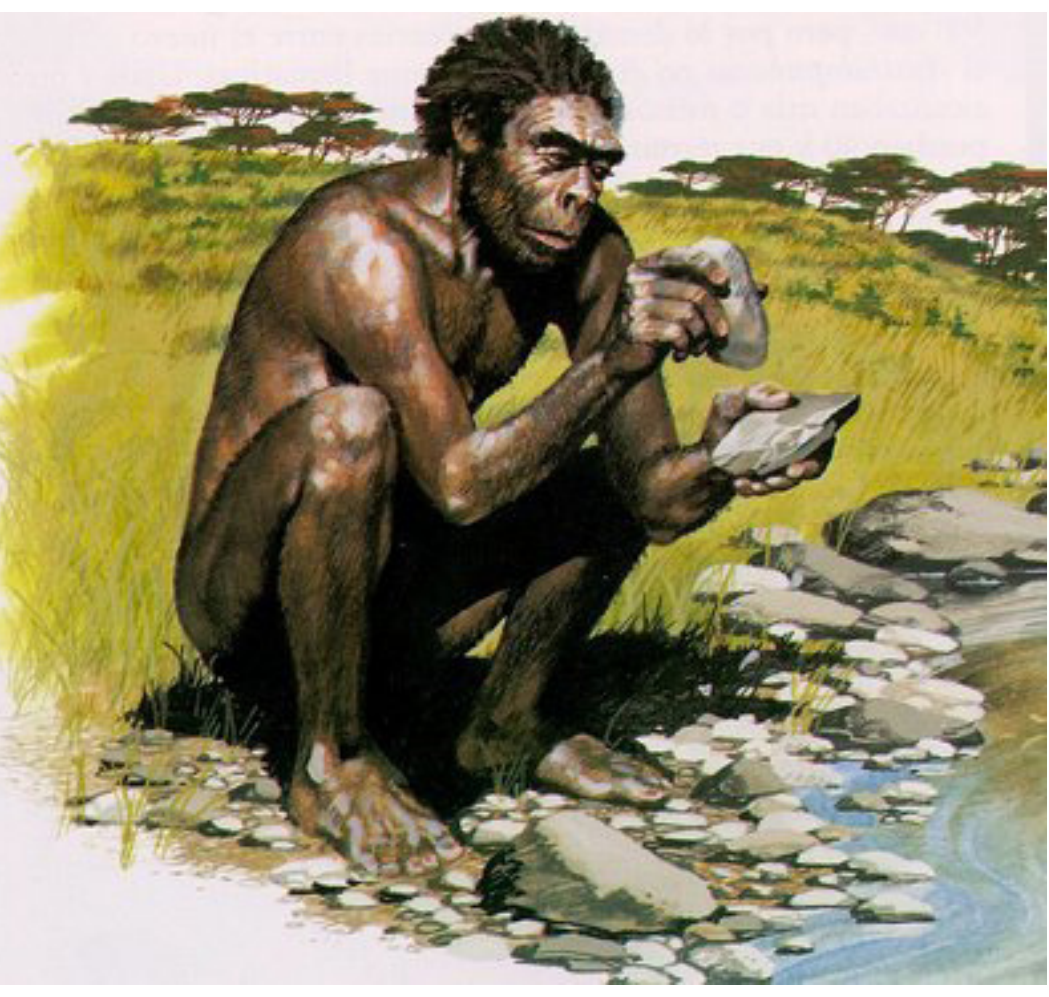

Figura 3. Construcción de herramientas de piedra. Recuperado de Wikimedia Commons. naturales para uso humano- fue ampliamente conocida por diversas comunidades. El uso de instrumentos de piedra por el hombre primitivo y sus antecesores se sitúa como una de las primeras manifestaciones de cultura, pues hay evidencia material de esa actividad, como es el caso de restos de herramientas en los vestigios fósiles. De ahí que muchos antropólogos consideren que el desarrollo cognitivo está asociado con el uso de herramientas (Ember, 2007).

\section{El desarrollo de la inteligencia}

El proceso de encefalización, como se denomina al aumento gradual del tamaño del cerebro, se dio bajo las condiciones climáticas adversas que prevalecieron durante la evolución de los homínidos, con una marcada la alternancia de períodos de frío y calor, humedad y sequía, en los últimos millones de años. Esto sugiere que la variabilidad ambiental ejerció presiones de selección natural. Las poblaciones de homínidos que tenían capacidad para enfrentar de forma versátil las inclemencias del clima sobrevivieron. Podemos suponer, entonces, que este proceso de evolución del cerebro homínido tuvo lugar en la medida que confiriera ventajas adaptativas. En otras palabras, si el cerebro, al incrementar su complejidad, fuera capaz de resolver problemas importantes para la supervivencia, la encefalización continuaría por ser exitosa para la especie. Si este cerebro capaz de resolver nuevos problemas también estuviera dotado para aprender, sería más ventajoso, porque podría almacenar y manejar información, así como compartirla con otros miembros de la comunidad. Y si le añadimos flexibilidad para ejecutar dichas funciones (almacenar y manejar información) a su capacidad para responder en circunstancias de fuertes fluctuaciones ambientales, tendría efecto positivo para la supervivencia de la especie. 
Figura 4. Utensilios de piedra. Recuperado de Akhilan, Wikimedia Commons.

1 Los últimos hallazgos en Marruecos sugieren que la especie podría remontarse a 315 mil años (Callaway, 2017).
Con la aparición del Homo sapiens hace alrededor de 200 mil años, ${ }^{1}$ se desarrolló un comportamiento con mayor capacidad para planear y comunicar ideas, lo que dio como resultado un incremento en la diversidad cultural e innovación técnica (Potts, 2012). La correlación que se observa entre el tamaño del cerebro —deducido por las dimensiones de los cráneos fósiles encontrados en las diversas especies prehumanas - y la tecnología desarrollada por estas poblaciones, cada vez más elaborada y diversa, nos dice, sin duda, que el incremento de la capacidad cerebral y de la inteligencia fueron construyendo los cimientos del portentoso edificio de la cultura.

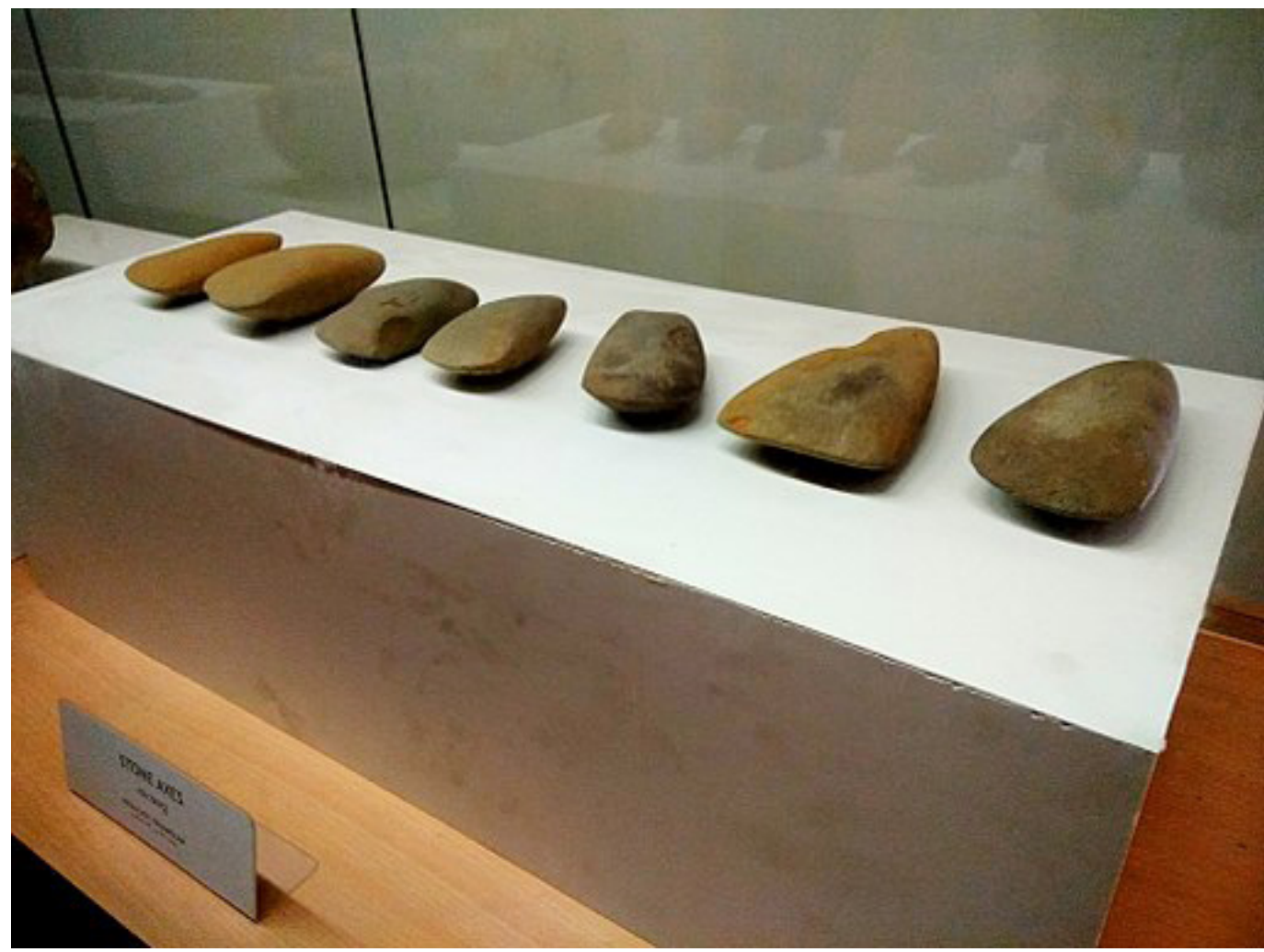

\section{Las ventajas de la vida en comunidad}

La evolución humana no se limita a modificaciones anatómicas y fisiológicas, pues incluye el desarrollo de aptitudes sociales y de conducta. La historia paleontológica del hombre muestra que el bipedalismo — andar erguido sobre dos extremidades - antecedió a la construcción de herramientas y armas, es decir, el que los homínidos caminaran en dos piernas permitió el libre uso de las manos. El incremento gradual de capacidades cognitivas favoreció que otras habilidades se desarrollaran, incluyendo, por supuesto, un comportamiento social más complejo. Cooperar para obtener el alimento dio a los ancestros del hombre oportunidades para sobrevivir incluso en los períodos de mayor 
pueblos a lo largo de la historia, y que se han ido transformando y transmitiendo de generación en generación hasta nuestros días (Altieri, 2001). La cultura es resultado de la inteligencia humana, su desarrollo y crecimiento ha facilitado la supervivencia de la especie, por lo cual se ha considerado como una ventaja adaptativa ante variaciones del medio ambiente (Richerson, 2005). Recordemos que en la Prehistoria sobrevivir a las fluctuaciones climáticas y competir por el alimento requería de ventajas. La constitución física de hombre prehistórico, aun cuando se tratara de cuerpos fornidos, no era suficiente. La única posibilidad de sobrevivir en circunstancias tan adversas era contar con habilidades para resolver situaciones complicadas y desafíos que no podrían ser superados sólo por los instintos, se requería, pues, de creatividad e ingenio.

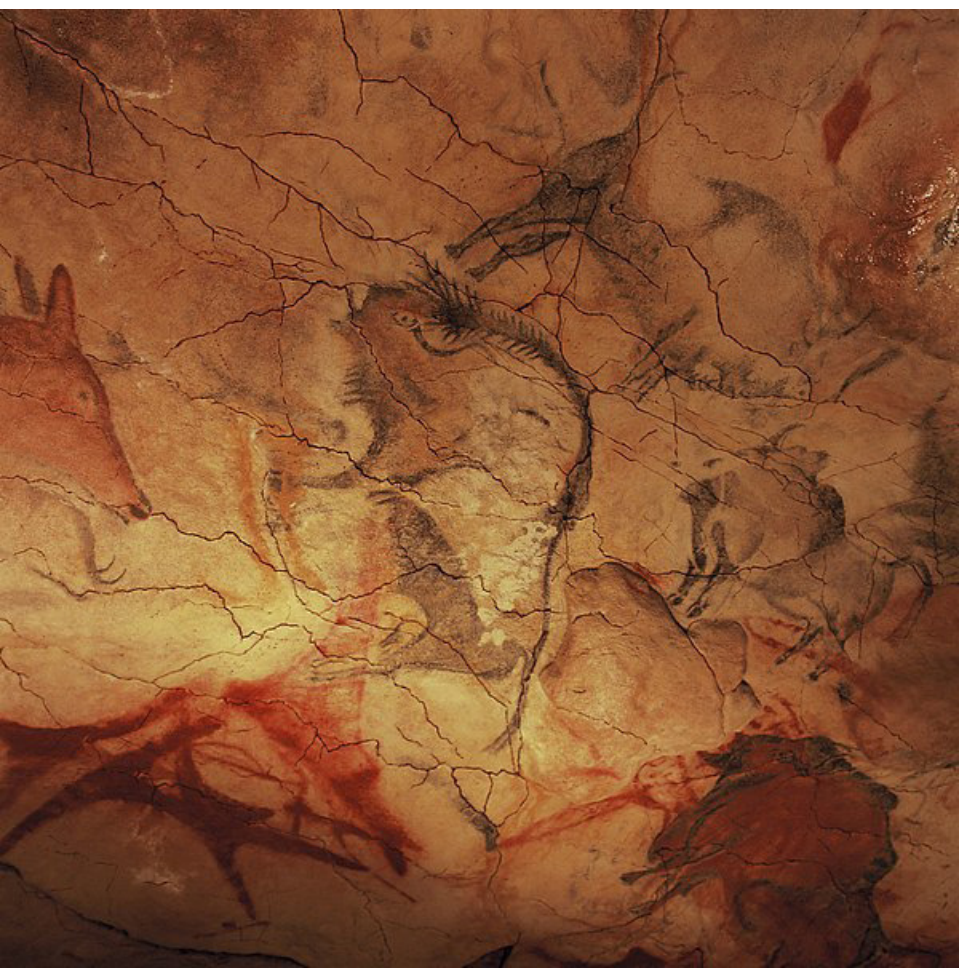

El ser humano es considerado como una especie exitosa, pero cuya supervivencia y expansión no alcanza a entenderse sólo con el desarrollo de una inteligencia avanzada. Los individuos no podrían llegar a dominar los conocimientos suficientes para sobrevivir en determinadas condiciones (Boyd, 2011). Si pensamos en la cantidad de información que maneja una comunidad, incluso una muy elemental, tendríamos que considerar que el conocimiento se incrementa con el paso del tiempo, de suerte tal que en algún momento rebasaría la posibilidad de que todo ese saber pueda ser abarcado por cada individuo, por lo que resulta conveniente dividirlo entre los miembros del grupo, como si éste se repartiera entre la población. Así ocurre con la división del trabajo, cada miembro se orienta hacia determinada ocupación.

La posesión de un bagaje cultural podría haber contribuido favorablemente a la supervivencia de grupos humanos. Adaptar el medio a las necesidades de los pobladores fue posible gracias a que gradualmente la inteligencia comunitaria - la suma de los intelectos

Figura 7. Arte rupestre. Recuperado de Yvon Fruneau, Wikimedia Commons. de un grupo social- desarrolló técnicas y conocimientos para mejorar sus condiciones de vida y transmitirlas a las generaciones venideras a través de la educación. El enfoque de la coevolución biológica y cultural, propuesta por Richerson y Boyd (2005) y otros autores, postula que la cultura surgió como un sistema que permite adaptarse con mayor versatilidad a condiciones cambiantes del medio ambiente. Este "sistema" es producto de la biología humana, ha sido modelado por la selección natural y si ha persistido es porque con toda seguridad ha proporcionado a las poblaciones humanas y prehumanas ventajas adaptativas. Varios autores conciben a la cultura como un sistema de información que puede adquirirse como resultado de la experiencia, el aprendizaje o la imitación. Esta información se almacena en el cerebro y tiene efecto sobre el comportamiento. La cultura permite de una manera eficaz e 
inmediata responder a los desafíos que plantea la supervivencia en entornos variables. La objeción a esta tesis es que le falta explicar cómo se relacionaría una ventaja cultural en términos genéticos, es decir, cómo la actividad cultural podría influir en el proceso evolutivo, ya que tendría que afectar la información contenida en los genes (Garson, 2015)

\section{¿Y el aprendizaje?}

El desarrollo de habilidades culturales, tales como la capacidad de aprender del otro y de acumular conocimientos, ha sido determinante en el desarrollo de la cooperación como una forma de interacción humana, que confirió ventajas adaptativas. También las emociones y sentimientos han sido de gran importancia para la vida humana, no sólo por su participación en los procesos cognitivos, el aprendizaje y las manifestaciones culturales, sino porque posiblemente desempeñaron un papel relevante en la evolución de la especie.

Si bien el cerebro reúne grandes cualidades, éstas no son propiedad exclusiva del órgano, sino del individuo como un sistema integral (Nieto, 2011). La presencia de elementos culturales ha permitido a las comunidades adecuarse a diversos entornos (Boyd, 2009). Así, frente a condiciones cambiantes del medio ambiente, como las que han caracterizado el tiempo en que las distintas especies de homínidos han poblado la Tierra, éstas sobrevivieron gracias a su capacidad de adaptación. El Homo sapiens, en tanto única especie de los homínidos que no se ha extinguido, debe su supervivencia y expansión geográfica a una gran adaptabilidad largamente labrada (Potts, 2012). No puede dejar de mencionarse que el hombre moderno apareció miles de años antes que las primeras civilizaciones. Esto parece indicarnos que el tránsito desde fabricar herramientas de piedra hasta construir ciudades requirió de un prolongado proceso de incubación. El paso fue gigantesco, el tiempo que tardó en darse fue largo.

Figura 8. Ruinas de Stonehenge. Recuperado de Wikimedia Commons.

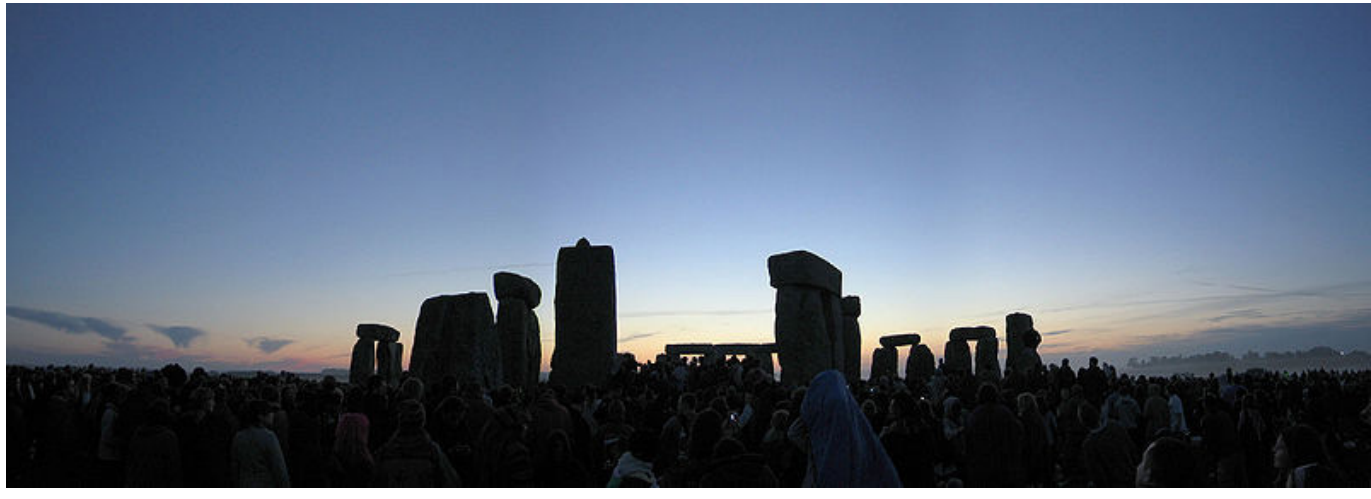

Podemos conjeturar que la selección natural ha favorecido a un cerebro que nos faculta para aprender flexiblemente, lo que se traduce en la capacidad de cambiar nuestro comportamiento, pues incorporamos tanto la experiencia como lo aprendido. Esto reduce lo que ha tenido que invertirse en información 


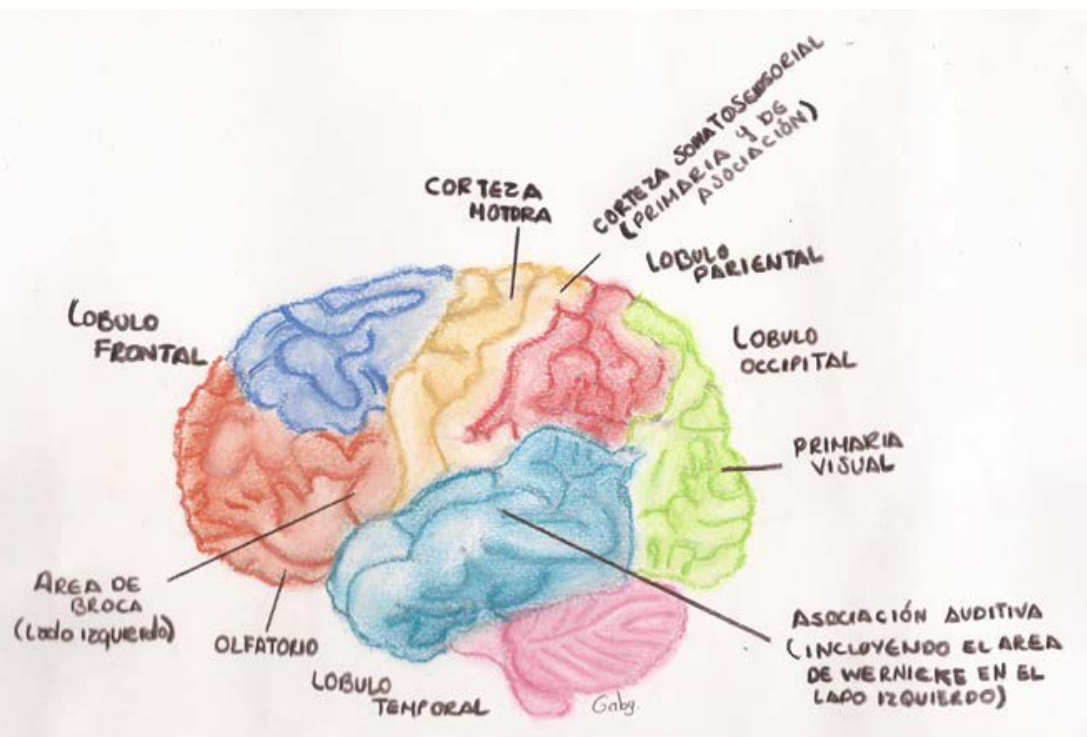

Figura 9. Cerebro humano. Dibujo cedido al autor por la estudiante Alejandra Gabriela Jiménez Reyes. heredable, pues de otro modo se tendría que determinar genéticamente cada comportamiento (Bartra, 2014). Hoy sabemos a ciencia cierta que el encéfalo está diseñado conforme con un programa genético que ha determinado sus propiedades innatas, es decir, aquellas con las cuales nacemos. También hay un control denominado epigenético, según el cual el ambiente y las condiciones de vida influyen en el desarrollo y funcionamiento (Purves, 2008). El aprendizaje puede ser visto como un agente externo que, de algún modo, "moldea" al cerebro. ¿Cómo lo hace? Las evidencias confirman que el aprendizaje produce cambios en este órgano (Miall, 2013), pues se han detectado zonas específicas que crecen cuando se desarrollan ciertas habilidades, que se pueden adquirir por experiencia o aprendizaje. Por ejemplo, se ha detectado que músicos profesionales presentan mayor volumen y espesor de materia gris en la corteza cerebral auditiva que los músicos amateurs o personas que no se dedican a este arte (Schneider et al., 2002). También hay indicios de que las prácticas y entornos culturales influyen directamente tanto en el comportamiento como en la morfología y actividad cerebral. Asimismo, hay conductas y expresiones culturales que pueden ser determinadas por la carga genética del individuo (Han, 2015).

\section{Modelo para armar}

Recapitulemos. El registro fósil muestra que en los últimos dos millones de años se incrementó el tamaño del cerebro. En este período, entre 800 mil y 200 mil años antes de nuestra era, se dio el mayor crecimiento del cerebro, que trajo como consecuencia mayor capacidad de memoria y de procesamiento de información. Así, el incremento de las habilidades cognitivas posibilitó el avance cultural de la humanidad (Tomasello, 2005). Por su parte, los acervos culturales que las comunidades fueron construyendo parecen haber influido en el desarrollo evolutivo de la especie, aunque no está claro cómo.

Consideramos la posibilidad de que la creación de la cultura facilitara la supervivencia, porque ayudaba a superar problemas. También parece razonable asumir que el conocimiento se ha expandido desde sus orígenes gracias a la notable capacidad de aprendizaje de la especie. Pero lo que todavía se plantea como suposición es considerar que la aparición de manifestaciones culturales como el manejo de herramientas, el uso del fuego y el surgimiento del lenguaje pudieran propiciar condiciones para que la selección natural favoreciera 
Figura 10. El Dr. Richard

Potts explica la evolución humana a visitantes del Museo Smithsoniano, en los E.U.A. Recuperado de https:// humanorigins.si.edu/. comportamientos que nos permitieran aprender del otro y que ampliaran el camino hacia la adquisición de conocimientos (Boyd, 2011). Incluso, se ha sugerido que el desarrollo del lenguaje proporcionó a los ancestros del hombre alguna ventaja evolutiva, quizá porque facilitó la cooperación. Aunque compartir información podría parecer desventajoso para el individuo (si pensamos que en un entorno de competencia por la supervivencia puede otorgarle la ventaja al competidor), a la postre pudo favorecer el desenvolvimiento social (Ulbaek, 1998).

En suma, el modelo para comprender la evolución de nuestra especie tiene que contemplar todas las variables que de algún modo intervinieron en el proceso y definir cuáles fueron determinantes para el desarrollo de la humanidad, incluyendo el peso específico con que pudieron haber contribuido nuestras capacidades de aprender y crear cultura.

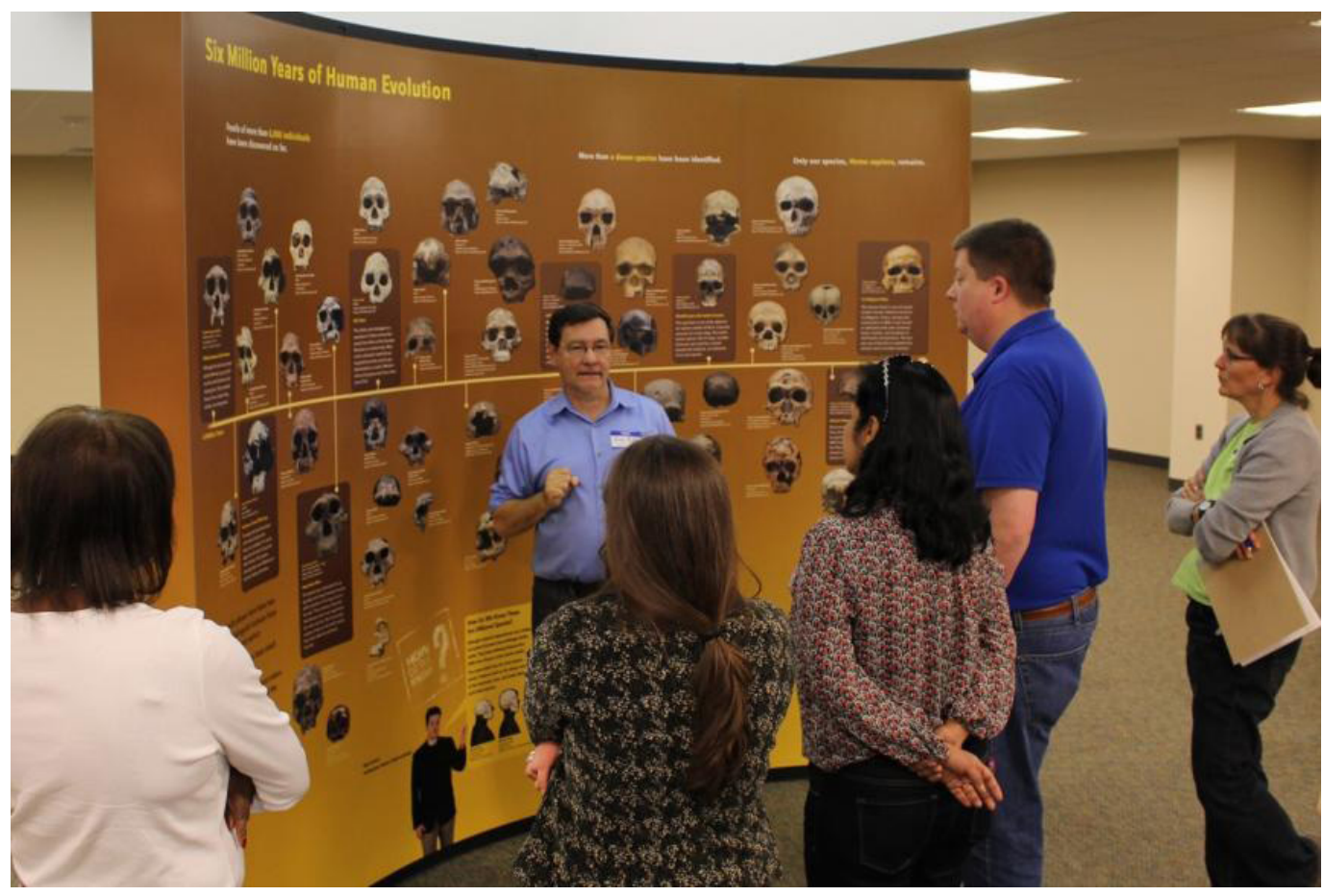

\section{Sitios de interés}

* Evolución humana (Museo Smithsoniano)

* Origen y evolución del ser humano (Revista ¿Cómo ves?)

* Diagrama que ilustra la evolución de los homínidos (Berkeley)

* Introducción a las salas de Prehistoria del Museo Arqueológico Nacional (video)

* El Explicador: La evolución del cerebro humano (podcast de Enrique Ganem)

* ¿Qué es el aprendizaje? (video de la Universidad Autónoma del Estado de Hidalgo) 


\section{Referencias}

* Altieri Megale, A. (2001, julio-diciembre). ¿Qué es la cultura?. La Lámpara de Diógenes, 2(4), 15-20. https://www.redalyc.org/pdf/844/84420403.pdf

* Bartra, R. (2014). Antropología del cerebro. Conciencia, cultura y libre albedrío [versión ampliada]. Pre-textos.

* Boyd, R., Richerson, P. J. y Henrich, J. (2011). The cultural niche: Why social learning is essential for human adaptation? PNAS, 108 [suppl. 2], 10918-10925. Dol: https:// doi.org/10.1073/pnas.1100290108

Boyd, R. y Richerson, P. J. (2009, 12 de noviembre). Culture and the evolution of human cooperation. Philosophical transactions of the Royal Society B, 364(1533), 3281-3288. Dol: https://doi.org/10.1098/rstb.2009.0134

- Callaway, E. (2017, 7 de junio). Oldest Homo sapiens fossil claim rewrite our species' history. Nature News. https://www.nature.com/news/oldest-homo-sapiens-fossilclaim-rewrites-our-species-\%20history-1.22114

Ember, C. R., Ember, M. y Peregrine, P. N. (2007). Anthropology. (12a ed.). Pearson.

* Garson, J. (2015). The biological mind. A philosophical introduction. Routledge.

* Gore, R. (2002). Primeros pasos. National Geographic en español, edición especial Los orígenes del hombre, 38-65.

Han, S.y Ma, Y. (2015). A culture-behavior-brain loop model of human development. Trends in Cognitive Sciences, 19(11), 666-676. Dol: https://doi.org/10.1016/j. tics.2015.08.010

* Leaky, M. (2002, verano). El horizonte más lejano. National Geographic en español, edición especial Los orígenes del hombre, 2-15.

Miall, C. (2013, 27 de agosto). 10,000 hours to perfection. Nature Neuroscience, 16, 1168-1169. Dol: https://doi.org/10.1038/nn.3501

* Nieto Gil, J. (2011). Neurodidáctica. Aportaciones de las neurociencias al aprendizaje y la enseñanza. ccs.

* Potts, Richard. (2012, octubre). Evolution and environmental change in early human prehistory. Annual Review of Anthropology, 41, 151-167. Dol: https://doi. org/10.1146/annurev-anthro-092611-145754

* Purves, D., Brannon, E. M., Cabeza, R., Huettel, S. A., LaBar, K. S., Platt, M. L. y Woldorff, M. G. (2008). Principles of cognitive neuroscience. Sinauer Associates.

* Richerson, P. J. y Boyd, R. (2005) Not by genes alone. How culture transformed human evolution. The University of Chicago Press.

* Schneider, P., Scherg, H. G. Dosch, Specht, H. J., Gutschalk, A.y Rupp, A. (2002, julio). Morphology of Hescht's gyrus reflects enhanced activation in the auditory cortex of musicians. Nature Neuroscience, 5(7), 688-694. Dol: https://doi.org/10.1038/ nn871 
* Tomasello, M., Carpenter, M., Call, J., Behne, T.y Moll, H. (2005). Understanding and sharing intentions: The origins of cultural cognition. Behavioral and Brain Sciences, 28(5), 675-691. Dol: https://doi.org/10.1017/S0140525X05000129

- Ulbaek, I. (1998). The origin of language and cognition. Social and cognitive bases. En J. R. Hurford, M. Studdert-Kennedy y C. Knight (Eds.), Approches to the evolution of language (pp. 30-43). Cambridge University Press.

\section{Cómo CITAR ESTE ARTículo}

- Urbina Orantes, Julio César. (2020, septiembre-octubre). ¿Influyeron la cultura y el aprendizaje en la evolución humana? Revista Digital Universitaria (RDU), 21(5). Dol: http://doi.org/10.22201/cuaieed.16076079e.2020.21.5.3 